Kroezen, M., Schäfer, W., Sermeus, W., Hansen, J., Batenburg, R. Healthcare assistants in EU member states: an overview. Health Policy: 2018, 122(10), 1109-1117

\begin{tabular}{|l|l|}
\hline $\begin{array}{l}\text { Postprint } \\
\text { Version }\end{array}$ & 1.0 \\
\hline Journal website & $\underline{\text { https://linkinghub.elsevier.com/retrieve/pii/S0168851018302458 }}$ \\
\hline Pubmed link & $\underline{\text { https://www.ncbi.nlm.nih.gov/pubmed/30033205 }}$ \\
\hline DOI & 10.1016/j.healthpol.2018.07.004 \\
\hline
\end{tabular}

This is a NIVEL certified Post Print, more info at http://www.nivel.eu

\title{
Healthcare assistants in EU Member States: An overview
}

\author{
MARIEKE KROEZEN ${ }^{\mathrm{A}, \star}$ WILLEMIJN SCHÄFER ${ }^{\mathrm{B}, \mathrm{C}}$, WALTER SERMEUS $^{\mathrm{D}}$, JOHAN \\ HANSEN $^{\mathrm{E}}$, RONALD BATENBURG ${ }^{\mathrm{E}, \mathrm{F}}$ \\ ${ }^{a}$ Erasmus MC, University Medical Center Rotterdam, Department of General Practice, P.O. \\ Box 2040, 3000 CA Rotterdam, The Netherlands \\ ${ }^{\mathrm{b}}$ Northwestern University, Feinberg School of Medicine, Department of Social Medical \\ Sciences, 625 N. Michigan Ave, $27^{\text {th }}$ Floor, Chicago, IL 60611, UnitedStates \\ 'North Shore University Health System, Department of Family Medicine, Research Institute, \\ 1001 University Place, Evanston, IL 60201, United States \\ ${ }^{d}$ KU Leuven Institute for Healthcare Policy (LIGB), University of Leuven, Kapucijnenvoer 35 \\ blok d - bus 7001, 3000 Leuven, Belgium \\ ${ }^{\mathrm{e}}$ Netherlands Institute for Health Services Research (NIVEL), P.O. Box 1568, 3500 BN \\ Utrecht, The Netherlands \\ ${ }^{\dagger}$ Radboud University Nijmegen, Department of Sociology, P.O. Box 9104, $6500 \mathrm{HE}$ \\ Nijmegen, The Netherland
}

\section{HIGHLIGHTS}

- The importance of healthcare assistants in healthcare systems is expected to grow.

- Most learning outcomes for HCAs across Europe are knowledge and skills-related.

- There appears to be a common, core set of learning outcomes for HCAs across

Europe

- Country differences can be explained by varying regulatory and educational frameworks.

\footnotetext{
Abstract

With many European countries facing health workforce shortages, especially in nursing, and an increasing demand for healthcare, the importance of healthcare assistants (HCAs) in modern healthcare systems is expected to grow. Yet HCAs' knowledge, skills, competences and education are largely unexplored. The study 'Support for the definition of core competences for healthcare assistants' (CC4HCA, 2015-2016) aimed to further the knowledge on HCAs across Europe. This paper presents an overview of the position of healthcare assistants in $27 \mathrm{EU}$ Member States (MSs) and reflects on the emerging country differences.
} 
It is shown that most learning outcomes for HCAs across Europe are defined in terms of knowledge and skills, often at a basic instead of more specialized level, and much less so in terms of competences. While there are many differences between MSs, there also appears to be a common, core set of knowledge and skills-related learning outcomes which almost all HCAs across Europe possess. Country differences can to a large extent be explained by the regulatory and educational frameworks in which HCAs operate, influencing their current and future position in the healthcare system. Further investments should be made to explore a common understanding of HCAs, in order to feed discussions at policy and organisational levels, while simultaneously investments in the development and implementation of context-specific HCA workforce policies are needed.

\section{INTRODUCTION}

With many European countries facing health workforce shortages, especially in nursing, as well as a growing number of chronically ill patients and an increasing demand for healthcare [1], the importance of healthcare assistants (HCAs) in modern healthcare systems is expected to grow strongly. HCAs now comprise a significant part of healthcare teams, working closely with registered nurses and other health professionals [2,3]. Their positions are proliferating across all healthcare settings [4] and they are undertaking a substantial number of tasks, as acknowledged by other health workers, including nurses [5]. The contribution of HCAs will most likely become increasingly important to maintain a sustainable health care system, and to secure patient care accessibility, safety and quality. Therefore, a good understanding of the HCA workforce is imperative. Not only to improve multidisciplinary collaboration, as clarification of team members' roles and responsibilities is known to be crucial for any well-functioning health organisation [6,7], but also in order to achieve (integrated) health workforce policies and planning [4]. After all, to ensure that the right number of people, with the right skills, are at the right place and time to deliver the right services to those in need of them [8], it is essential to have a complete overview of all professions working in the health system.

However, the HCA workforce is still largely invisible, as was recently concluded by a comprehensive scoping review of the HCA workforce literature [4], leaving HCAs' knowledge, skills, competences and education largely unexplored. It has been noted that HCAs go by many titles, have heterogeneous roles and are largely unregulated (including the fact that they do not fall under Directive 2005/36/EC on the automatic recognition of professional qualifications), but it is yet poorly understood how this varies between countries and how the profession evolves. Most of the current literature focuses either on the U.S.A. or Canada [4], whereas little is known about HCAs in European countries. The lack of knowledge concerning HCAs hampers the possibility of European governments and healthcare organizations to achieve an optimal division of tasks within multidisciplinary teams, to develop and implement effective workforce policies and, ultimately, to provide high-quality patient care. In order to progress on these point, the delineation of HCAs' knowledge, skills, competences and scope of practice is essential. 
Kroezen, M., Schäfer, W., Sermeus, W., Hansen, J., Batenburg, R. Healthcare assistants in EU member states: an overview. Health Policy: 2018, 122(10), 1109-1117

\subsection{The study 'Support for the definition of core competences for healthcare assistants' (CC4HCA)}

In order to fill the knowledge gap on HCAs in Europe, the European Commission in 2009 funded a pilot network of nurse educators and regulators [9]. In 2012, this pilot network performed a first mapping exercise on the role and position of HCAs in fourteen EU Member States. Based on questionnaire research among key informants, country profiles were developed which mapped the educational, regulatory and employment related characteristics of HCAs across the 14 included Member States [9]. Based on the outcomes of this pilot network, the European Commission in 2015 decided to fund the study 'Support for the definition of core competences for healthcare assistants' (CC4HCA) under the Third Health Programme 2014-2020. One of the aims of the CC4HCA study was to provide an overview of the position of HCAs in all 28 EU Member States. This paper presents and elaborates on the results of the CC4HCA study.

\subsection{Aim and research questions}

The aim of this paper is to present an overview of the current position of healthcare assistants in the EU Member States and to reflect on the country differences that emerge from this overview. The following research questions are addressed and build the structure of the paper:

What are the knowledge, skills and competences of HCAs across EU Member States?

1 What are the characteristics of the educational framework for HCAs across EU Member States in terms of minimum age, entry requirements, duration, theorypractice ratio and Continuing Professional Development (CPD)?

2 How are HCAs regulated across EU Member States in terms of education and profession?

3 To what extent does the position of HCAs differ across EU Member States and how can this be explained?

\section{METHODS}

To provide an overview of the current position of healthcare assistants in all $28 \mathrm{EU}$ Member States, the CC4HCA study conducted a survey among key informants (i.e. national experts) from the 14 Member States that were not covered by the pilot study [9], being: Croatia, Cyprus, Estonia, France, Greece, Hungary, Latvia, Lithuania, Luxembourg, Malta, Portugal, Romania, Slovakia and Sweden. Survey data from the 14 Member States that were included in the pilot study - Austria, Belgium, Bulgaria, Czech Republic, Denmark, Finland, Germany, Ireland, Italy, the Netherlands, Poland, Slovenia, Spain and the United Kingdom - were updated where necessary and reanalysed.

\subsection{Questionnaire research}

The CC4HCA questionnaire was largely based on the questionnaire used in the pilot study [9] to maximize comparability between the data collected in both studies. However, after explorative desk and literature research, additional items of interest were included in the CC4HCA questionnaire, such as continuous professional development for HCAs and employment and labour markets for HCAs. To enhance content validity, a preliminary version of the CC4HCA questionnaire was reviewed by external experts in the Netherlands and Hungary as well as project officers at DG 
SANTE/CHAFEA. Based on their feedback, adjustments were made and incorporated in the final version of the questionnaire. The final questionnaire consisted of 24 multi-part open questions and was divided in four main sections, being:

1 Definitions and job descriptions of HCAs;

2 HCA education;

3 Regulation and registration of HCAs; and

4 Employment and labour markets for HCAs.

A copy of the CC4HCA questionnaire can be obtained by email from the authors.

\subsection{Data collection}

Data collection for the CC4HCA study took place in July and August 2015. The questionnaire was sent by email to key informants in the 14 EU Member States that were not part of the pilot study (see above for the list of countries). Key informants were selected based on their expertise regarding HCAs in their national context, using the professional networks of the CC4HCA project consortium and other relevant networks, such as the member list of the International Council of Nurses. All key informants received instructions on how to complete the questionnaire and were asked to return it by email. As HCAs go by many titles and are not defined by one line of reference [4], no formal definition of HCAs was provided to respondents. Rather, informants were asked to provide the "appropriate occupational name(s) or title(s)for what can be defined as "healthcare assistants" in their country, both in their national language and in English, and answer the questions in the questionnaire for these group(s). To validate the information that was provided, key informants were explicitly invited to share their preliminary answers to the questionnaire with other experts in their national professional networks (this enabled the option that multiple people contributed to one questionnaire). In addition, informants were asked to complement their answers with references to national laws, literature, educational curricula and other relevant sources. The completed questionnaires were checked by the CC4HCA study team upon reception and sent back to the key informants to resolve any ambiguities or uncertainties in the data provided.

To ensure that the data from the pilot study countries [9] were up to date, all key informants who had been responsible for data collection in 2012 were approached again and asked by e-mail to update the data on their country, should major changes have taken place since 2012. Updates were received from Austria, Ireland, Italy, the Netherlands and Slovenia. The updated data were used in the current analyses. For the remaining countries, the answers to the pilot study in 2012 were used.

\subsection{Data analysis}

We performed descriptive analysis in Excel using univariate statistics on a large number of aspects of the HCA role and position in the EU Member States. To ensure comparability between the data that were provided by key informants through the pilot study questionnaire and the CC4HCA questionnaire, we followed a three-step process.

First the European Qualifications Framework (EQF) - a reference framework to help compare national qualification systems - was used to categorize and analyse the answers that the respondents provided in their own words, i.e. in free format. Two researchers independently listed the answers on all relevant questionnaire items under one of the three key EQF descriptors [1] knowledge [2], skills or [3] 
competences [10]. Disagreements were resolved through consensus. For example, one key informant stated that HCAs" "areas of activities include the feeding of the patients". We categorized this answer as a HCA skill and did likewise with similar answers from the other country experts.

Secondly, two reviewers independently performed a more detailed sub-categorization of the answers under the three descriptors knowledge, skills and competences. This was based on four existing frameworks for defining the range of knowledge, skills and competences expected of nursing and related professions:

1 The ICN Nursing Care Continuum Framework and Competencies [11];

2 The EFN Matrix on the 4 Categories of the Nursing Care Continuum [12];

3 The EFN Competency Framework [13]; and

4 The mapping used by Hewko et al. in their review [4].

Again, disagreements were resolved through consensus. The before mentioned example - the HCA skill "areas of activities include the feeding of patients" - was placed under the specific skill sub-category "patient care: nutrition", using this framework.

Third, all key informants' answers, categorized by the three EQF descriptors and its sub-categories, were translated into so-called 'learning outcomes'. This was done jointly by two researchers and based on the directions of the 'Using Learning Outcomes European Qualifications Framework Series: Note 4' by the EQF advisory group [14]. Learning outcomes are a well-accepted tool to facilitate comparisons between different educational systems and frameworks in Europe. They are defined as statements of what a learner knows, understands and is able to do on completion of a learning process [14]. When applied to the example of skill subcategory "patient care: nutrition", this was translated into the learning outcome "Prepare and serve food and drinks to clients/patients". The final list of learning outcomes served as the basis for our descriptive analysis of HCAs' knowledge, skills and competences across EU Member States, as presented in the next section.

\section{RESULTS}

\subsection{Response}

Regarding the 14 questionnaires that were sent out to EU Member States (MSs) as part of the CC4HCA study, 17 informants contributed to responses from the $14 \mathrm{MSs}$, producing a $100 \%$ response rate. The pilot study in 2012 achieved a $100 \%$ response rate as well, with 23 informants contributing to 14 returned questionnaires from 14 MSs. As mentioned above, the CC4HCA study also received updates on the pilot study data from Austria, Ireland, Italy, the Netherlands and Slovenia. A special note should be made about Germany, Finland and the UK, that were included in the pilot study. While the UK comprises four countries (England, Scotland, Northern Ireland and Wales), the answers for all four were presented jointly as UK answers by the country informants in the pilot study. In the case of Germany, a federal state, data was only available for the state of Lower Saxony (this is indicated in the results). Finally, data for Finland, collected by the pilot study, are not included in this paper as the CC4HCA study team was informed that the data for Finland are outdated. 
Kroezen, M., Schäfer, W., Sermeus, W., Hansen, J., Batenburg, R. Healthcare assistants in EU member states: an overview. Health Policy: 2018, 122(10), 1109-1117

\subsection{Knowledge, skills and competences learning outcomes of HCAs across EU Member States}

Table 1 presents an overview of the knowledge, skills and competence learning outcomes that are included in HCA curricula across EU Member States. If we look at these learning outcomes at country level, large differences become visible. The total number of learning outcomes is highest in France, Latvia, Luxemburg and Portugal with over 20 learning outcomes included in the HCA curriculum - and lowest in Denmark, Germany (Lower Saxony), Greece, Ireland and Slovenia - with only 8 or less learning outcomes included in the HCA curriculum.

\section{[TABLE 1]}

Most learning outcomes for HCAs across Europe are defined in terms of knowledge and skills, and much less so in terms of competences. While none of the identified knowledge learning outcomes is part of HCAs' curriculum in all European MSs, there are a number of items which are part of HCAs' curriculum in the majority of MSs, most notably:

- knowledge on support in the activities of daily living;

- knowledge on clerical, administrative and planning tasks; and

- knowledge on communication and interaction with patients and co-workers.

Moreover, in more than one-third of the Member States HCAs are trained to be knowledgeable about patient rights, ethics, relevant legislation, end-of-life care and inter-professional teamwork, among others. More specialised knowledge, concerning specialist areas of care and specific patient groups, is significantly less often part of the learning outcomes that HCAs should possess. In countries with a high total number of learning outcomes for HCAs, such as France, Luxembourg and Portugal, these more specialised learning outcomes are often part of the curriculum.

In terms of the skills-related learning outcomes that HCAs need to achieve at the end of their education, there is more resemblance between European MSs. Table 1 shows that most of the skills-related learning outcomes that were identified are part of HCA education in the majority of MSs. Especially more 'general' skills are often part of HCA education, such as monitoring and measuring patient parameters, preparing and serving food and drinks, and cleaning. More specialised skills, such as discharge and transfer of patients, are less often part of the learning outcomes that HCAs should possess. This is in line with the findings concerning knowledge-related learning outcomes.

Only a few MSs have formulated competences-learning outcomes for HCAs. These are mostly related to the care process and the patient rather than to actual care provision.

\subsection{Characteristics of the educational framework for HCAs across EU Member States}

The educational framework for HCAs differs considerably between EU Member States (see Table 2). In almost one third of the MSs there is no minimum age to enter HCA education (CY, DK, GR, IE, MT, NL, PT, SE, UK). In other MSs, minimum ages range from 15 to 20 years, with a median of 16.5 years. Entry requirements for HCA education also differ (not displayed in Table, see Appendix 1). In four MSs, there are no entry requirements at all (BG, LV, MT, NL for level 1). In most other 
MSs, entry requirements are either completion of elementary education (CZ, EE, HR, HU, IT, PT, SE, SI, SK, RO) or secondary education (AT, BE, CY, DE, EE, ES, GR, LT, LU, PL, SK, UK). In five countries, additional criteria have been formulated, mostly related to pre-admission medical check-ups (AT, CZ) or alternative ways for entry based on prior work experience in the healthcare sector (DK, FR, IE). The duration of the educational programmes is variable, ranging from 3 months (LT, $\mathrm{RO})$ to a maximum of 6 years (LV). Five MSs offer short-term programmes of less than a year (DK, FR LT, RO, IE), but most other MSs have one-year (AT, BE, IT), two-year (DE, EE, ES, GR, HU, PL, SE) or three-year (LU, PT) programmes in place. In a number of Eastern European countries, HCA education lasts for four years (CZ, HR, SI, SK). In a minority of MSs, the duration of education is dependent on the particular type of HCA course that is followed (CY, MT, NL).

In terms of the theory-practice ratio, there is a tendency towards more theory-based HCA education across Europe. Five countries have a 50:50 ratio of theory to practice (AT, BE, HU, LU, SK). In countries without a standard divide, the education is always based on both components (BG, HR, IE, MT, NL, UK). In ten countries, the content of the HCA curriculum is (much) more dominated by the theoretical part (CY, DE, EE, ES, GR, IT, PL, PT, SE, SI), while in five countries the practical component prevails slightly over the theoretical component (CZ, DK, FR, LT, RO). Information on Continuous Professional Development (CPD) requirements for HCAs is only available for half of the EU Member States. In four MSs, no CPD requirements have been set for HCAs (CY, GR, MT, SE). In most other Member States for which information is available, CPD is obligatory (HR, EE, FR, HU, LV, LU, RO, SK), for two it is optional (LT, PT).

3.4. Regulation of HCAs across EU Member States

In 21 EU Member States in which HCAs exist as a profession, both the education and the profession are regulated (AT, BE, BG, CY, CZ, DE, DK, ES, FR, GR, HU, IT, LT, LV, LU, NL, PL, RO, SI, SK, SE). Remarkably, in Portugal and Estonia the education is regulated but not the profession. Further information on Portugal reveals that the regulation of professions is only applicable for 'technical professions' with an EQF level of 6 or higher (which is not the case for HCAs according to Portuguese law). In Estonia, there are simply not enough HCAs at the moment to regulate the profession. In the English-speaking Member States - Ireland, Malta and the UK neither the HCA profession nor the education are regulated. In Croatia, there is no regulation because HCAs as such do not exist.

3.5. Differences between EU Member States in the position of HCAs As we concluded from Table 1, EU Member States differ considerably in the number of knowledge, skills and competence learning outcomes that they included in HCA curricula. The total number of learning outcomes is highest in France, Latvia, Luxemburg and Portugal (over 20) and lowest in Denmark, Germany (Lower Saxony), Greece, Ireland and Slovenia (8 or less). To understand this country variation, we related the number of learning outcomes in a country's HCA curriculum to the level of regulation of HCAs. Countries were grouped according to their regulatory structure for HCAs: no regulation (HR, IE, MT, UK); education regulation only (EE, PT); and both education and profession regulation (all other 21 EU MSs). The expectation was that in countries where the entry to HCA education and profession are not regulated, the HCA curriculum is less extensive in terms of knowledge, skills and competence learning outcomes, compared to countries that 
have either one or both entries regulated. Fig. 1 presents the outcomes of this analysis. There are clear differences between the four non-regulating countries and the regulating countries, in particular with regard to the average number of knowledge and competence learning outcomes in the HCA curriculum. Portugal and Estonia - the two countries which only regulated HCA education and not the profession - stand out from the other groups with higher average numbers of all items - but this result should be interpreted with caution as it is based on only two countries.

\section{[FIGURE 1]}

To further explore the differences in the position of HCAs across EU Member States, we checked whether the groups of MSs with [1] no regulation [2], education regulation only and [3] both education and profession regulation, differ in terms of the educational frameworks in place for HCAs (as presented in Table 2).

The expectation was that in countries without regulation, the criteria applied in educational frameworks would be less strict compared to the other groups of countries - with a lower minimum age to enter the education, a shorter duration of education and a less extensive training period in practice. This is indeed the case (analysis not shown):

- The average age to enter education is 15 years (or not specified) for countries with no regulation, 16,5 years for countries where both education and profession are regulated, and 18 years for countries which only regulated the education.

- The average duration of education is also shortest for countries with no regulation ( 0,8 years) compared to countries with educational and professional regulation $(2,1$ years), and education regulation only (2,5 years).

- For countries with no regulation, there is no standard theory-practice ratio for training (although both aspects are covered), while the theory-based component of the education is much larger in countries where the profession is not regulated ( $82,5 \%$ of the education on average) than in countries where the profession is regulated $(56,3 \%$ of the education on average).

Finally, to fully understand the variation in total numbers of learning outcomes across EU Member States, we related the number of learning outcomes in a country's HCA curriculum to the theory-practice ratio of the curriculum (as presented in Table 2). Fig. 2 shows that countries with a more theory-based curriculum include more knowledge learning outcomes in their curriculum than countries with a more practice-based curriculum (7,6 versus 5,2 respectively). Countries with a more practice-based curriculum include a higher number of skills-related learning outcomes (7,4 versus 6,2 respectively) and also the overall highest number of competence learning outcomes.

\section{[FIGURE 2]}

\section{DISCUSSION}

Our study showed that in most EU Member States, the knowledge and skills which healthcare assistants are expected to achieve as learning outcomes, are situated at a general or basic care level, much less so on a more specialised level. Competence learning outcomes are rarely defined for HCAs. While our study confirms the earlier observation that HCAs have heterogeneous roles [4], it also shows that there 
presumably is a common, core set of knowledge and skills-related learning outcomes which almost all HCAs across Europe possess. This finding may contribute to the common understanding of what HCAs are and what role they (should) play in care provision, for example in discussions at policy and organisational levels. As mentioned by Hewko et al. [4], having a universally accepted set of knowledge, skills and competences for HCAs may help to find the optimal setting-specific skillmix and division of tasks within multidisciplinary teams.

In order to increase the opportunities of European governments and healthcare organizations to develop and implement effective HCA workforce policies, we analysed the emerging country variation in terms of total numbers of HCA learning outcomes by relating these numbers with the underlying HCA regulatory and educational frameworks. In MSs with a lower total number of learning outcomes for HCAs, there is often no regulation for HCAs and the criteria applied in HCA educational frameworks are less strict compared to other countries (both in terms of minimum age and duration of the education). In MSs with a higher total number of learning outcomes for HCAs, the HCA education and profession are often both regulated, while there is often a higher minimum age to enter the education and on average a longer training duration. The exception is formed by the total number of skills learning outcomes, which is on average highest in countries with no regulation. It was also found that those Member States which have on average the most knowledge learning outcomes included in HCA curricula, are the MSs which have the most theory-based HCA curricula. In MSs with relatively more skills and competence items included in HCA curricula, HCAs spend more time in practice during their training. While this may seem obvious, it also points out the importance of adjusting HCAs' learning outcomes to their current and future roles in practice. After all, where HCAs already spend much of their time in practice, the relative importance of understanding and acting upon the division of responsibilities in healthcare (a competence) increases significantly.

Finally, we included two MSs in our analyses which only regulated HCA education and not the profession (Estonia and Portugal). While conclusions for these two countries can only be drawn cautiously, it is remarkable that these MSs had the highest average number of learning outcomes in their curricula, the highest average minimum age to enter education and the highest average duration of HCA training, which was predominantly theory-based. The latter may be explained by the lack of necessity to formally prepare students to enter the HCA profession, which is not regulated in these countries.

The results of our country variation analysis provide important input for countries aiming to develop and implement effective HCA workforce policies. It was shown that HCAs' professional scope (i.e. the total number of learning outcomes they possess) is related to the regulatory and educational frameworks in which they operate, and hence their current and future position in the healthcare system.

Naturally, the specific interpretation of the HCA role is to a large extent context- and setting dependent and is influenced by the particular health workforce needs and possibilities of each country. Yet, some important observations can be made. In countries where HCA students spend less time in practice during their training, it seems to be important to arrange more support, especially in terms of skills and competence related learning outcomes, once HCAs enter the labour market. Also, in terms of multidisciplinary working, it was noted that more specialised learning 
outcomes are often not yet included in HCA curricula. In care settings that are becoming increasingly specialized, with a higher reliance on multidisciplinary working, the importance of specialized knowledge for HCAs is increasing as well. One opportunity to meet this need may be by introducing setting-specific streams of training for HCAs. Also, it should be noted that in countries with a lower total number of learning outcomes for HCAs, their opportunities for professional advancement may be limited. This may influence the additional educational opportunities offered to HCAs, in order to retain them in the workforce.

Finally, our study showed that there are still considerable knowledge gaps concerning the HCA profession, for example in terms of their CPD requirements. More up-to-date research on their formal position, their specific role in practice and potential to contribute to multidisciplinary working is recommended.

\subsection{Strengths and weaknesses}

Several limitations of the study bear mentioning. First, the study relied on data reported by country informants. Although these key informants were selected on the basis of their national expertise and were asked to substantiate their answers with relevant sources and other material, we cannot guarantee the correctness of all answers provided as there was no possibility within the timeframe of the study to verify them against other sources. Secondly, it cannot be ruled out that data from the pilot study [9] for which no update was received after a request by the CC4CHA study team may be outdated at points. Finally, as already pointed out in the results section, the answers for all four countries in the UK (England, Scotland, Northern Ireland and Wales) were presented jointly as UK answers by the country informants in the pilot study. In the case of Germany, a federal state, data was only available for the state of Lower Saxony. This limits the generalizability of these data to the entire countries.

Naturally, our study does not present a complete picture of the position of healthcare assistants across EU Member States, nor does it claim to do so. Yet considering the few studies currently available, the findings of this study are a significant contribution to the knowledge base on HCAs across Europe. Moreover, a major strength of this study is its inclusive approach, focusing on the regulatory and educational aspects surrounding HCAs as well as HCAs' knowledge, skills and competences. Most publications take a narrower view and focus on one aspect only, such as education [15] or regulation [16]. By linking these various aspects in our study, a more complete picture of the HCA profession emerges, which is important in order to inform health workforce policies.

\section{CONCLUSIONS}

While European Member States differ in terms of the knowledge, skills and competences which healthcare assistants are expected to achieve as learning outcomes, the CC4HCA study shows that there presumably is a common, core set of learning outcomes which almost all HCAs across Europe possess. It may be beneficial for countries to further explore this common understanding of HCAs to feed discussions at policy and organisational levels, for example concerning the role that HCAs (should) play in care provision. At the same time, the country variations that emerged from this study, largely explained by the varying regulatory and educational frameworks in which HCAs operate, call for a context-specific approach. The results of the CC4HCA study, as presented in this paper, may provide important 
Kroezen, M., Schäfer, W., Sermeus, W., Hansen, J., Batenburg, R. Healthcare assistants in EU member states: an overview. Health Policy: 2018, 122(10), 1109-1117

input for countries aiming to develop and implement effective HCA workforce policies.

\section{Conflict of interest statement}

None of the authors has any potential conflict of interest related to this manuscript.

\section{Acknowledgements}

The study 'Support for the definition of core competences for healthcare assistants' (CC4HCA) was funded by the EU Health Programme (2014-2020) in the frame of a service contract with the Consumers, Health and Food Executive Agency (Chafea) acting under the mandate from the European Commission. The content of this article represents the views of the contractor and is its sole responsibility; it can in no way be taken to reflect the views of the European Commission and/or Chafea or any other body of the European Union. The European Commission and/or Chafea do not guarantee the accuracy of the data included in this article, nor do they accept responsibility for any use made by third parties thereof. The funding source had no involvement in the conduct of the study but approved of the decision to submit this article for publication. The authors wish to thank Zoltán Aszalos (Semmelweis University, Hungary) and dr. Zoltán Balogh (Chamber of Hungarian Health Care Professionals, MESZK, Hungary) as members of the CC4HCA study consortium for their contributions to the project, without which this article would not have been possible. The authors also wish to thank all key informants who contributed to the accomplishment of the CC4HCA study.

\section{APPENDIX A. SUPPLEMENTARY DATA}

\section{REFERENCES}

[1] M. Kroezen, G. Dussault, I. Craveiro, M. Dieleman, C. Jansen, J. Buchan, et al. Recruitment and retention of health professionals across Europe: a literature review and multiple case study research Health Policy, 119 (12) (2015), pp. 1517-1528

[2] L.I. MacAlister Have enrolled nurses just been reinvented? British Journal of Nursing, 7 (7) (1998), p. 365

[3] L. Vail, S. Bosley, M. Petrova, J. Dale Healthcare assistants in general practice: a qualitative study of their experiences Primary Health Care Research \& Development, 12 (1) (2011), pp. 29-41

[4] S.J. Hewko, S.L. Cooper, H. Huynh, T.L. Spiwek, H.L. Carleton, S. Reid, et al. Invisible no more: a scoping review of the health care aide workforce literature BMC Nursing, 14 (1) (2015), p. 38

[5] S. Bach, I. Kessler, P. Heron Nursing a grievance? The role of healthcare assistants in a modernized national health service Gender Work \& Organization, 19 (2) (2012), pp. 205224

[6] G. Williams, P. Laungani Analysis of teamwork in An NHS community trust: An empirical study Journal of Interprofessional Care, 13 (1) (1999), pp. 19-28

[7] E. Kelleher, J.M. Harrington, F. Shiely, I.J. Perry, S.M. McHugh Barriers and facilitators to the implementation of a community-based, multidisciplinary, family-focused childhood weight management programme in Ireland: a qualitative study BMJ Open, 7 (8) (2017), p. e016459

[8] M. Kroezen, M. Van Hoegaerden, R. Batenburg The Joint action on health workforce planning and forecasting: results of a European programme to improve health workforce policies Health Policy, 122 (2018), pp. 87-93

[9] Contec Development and coordination of a network of nurse educators and regulators (SANCO/1/2009) Contec GmbH, Bocum: Germany (2014) 
Kroezen, M., Schäfer, W., Sermeus, W., Hansen, J., Batenburg, R. Healthcare assistants in EU member states: an overview. Health Policy: 2018, 122(10), 1109-1117

[10] European Parliament and Council Recommendation of the European parliament and of the council of 23 April 2008 on the establishment of the European qualifications framework for lifelong learning (text with EEA relevance) (2008/C 111/01) Brussels: Official Journal of the European Union (2008) C 111/2 6.5.2008. Report No

[11] Nurses Ico Nursing care continuum framework and competencies. Geneva (2008)

[12] Committee EW EFN matrix on the 4 categories of the nursing care continuum. Brussels (2014)

[13] Associations EfoN EFN competency framework. EFN guideline to implement Article 31 into national nurses' education programmes European Federation of Nurses Associations, Brussels (2015)

[14] Union E Using learning outcomes European qualifications framework series: note 4 Publications of the European Union, Luxembourg (2011)

[15] S.C. Webb Education for healthcare assistants working in acute NHS hospitals Nursing Standard (through 2013), 25 (41) (2011), p. 41

[16] L. Storey Regulation of healthcare assistants: an ongoing debate British Journal of Healthcare Assistants, 1 (1) (2007), pp. 15-17 
Kroezen, M., Schäfer, W., Sermeus, W., Hansen, J., Batenburg, R. Healthcare assistants in EU member states: an overview. Health Policy: 2018, 122(10), 1109-1117

\section{TABLES AND FIGURES}
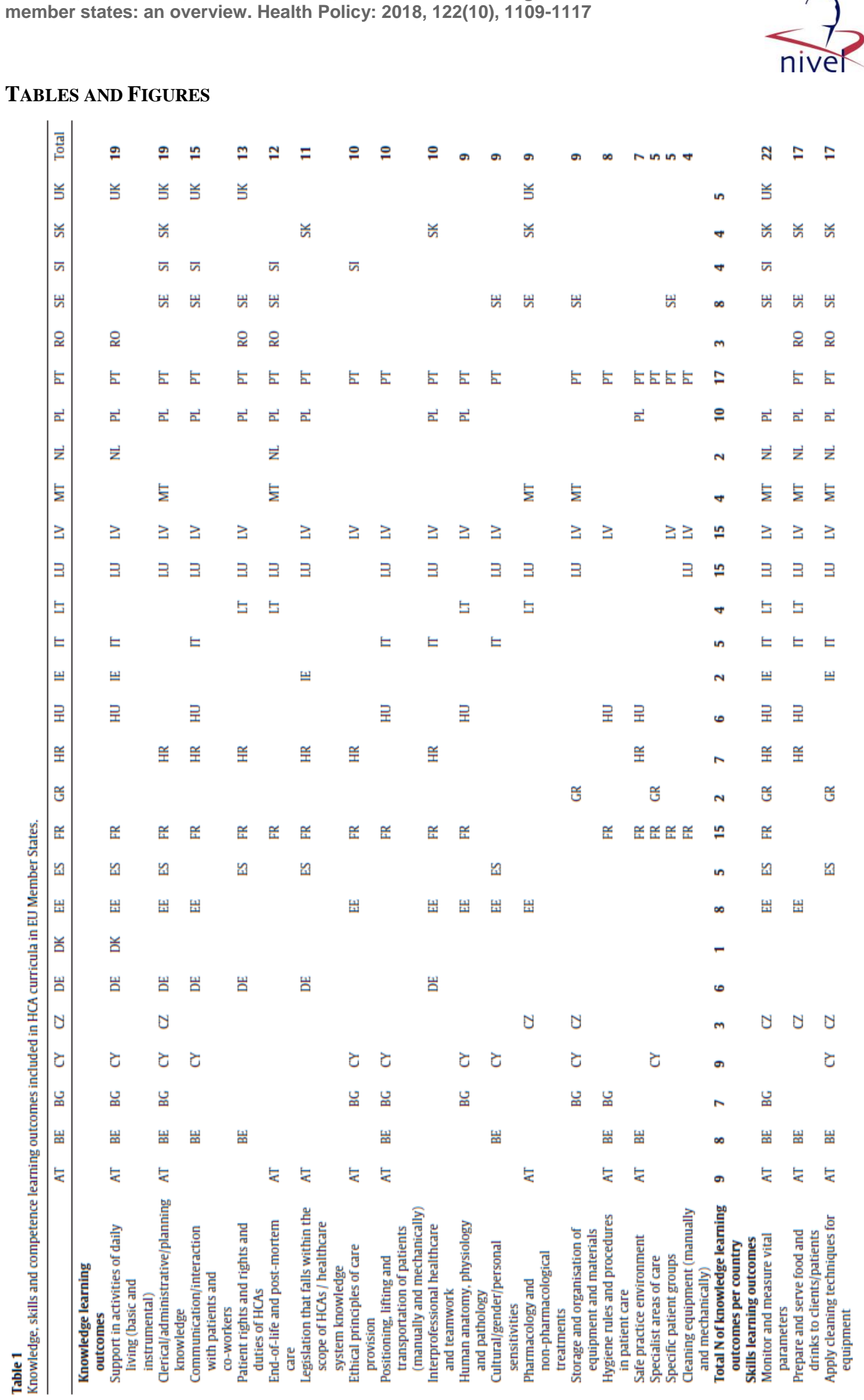
Kroezen, M., Schäfer, W., Sermeus, W., Hansen, J., Batenburg, R. Healthcare assistants in EU member states: an overview. Health Policy: 2018, 122(10), 1109-1117

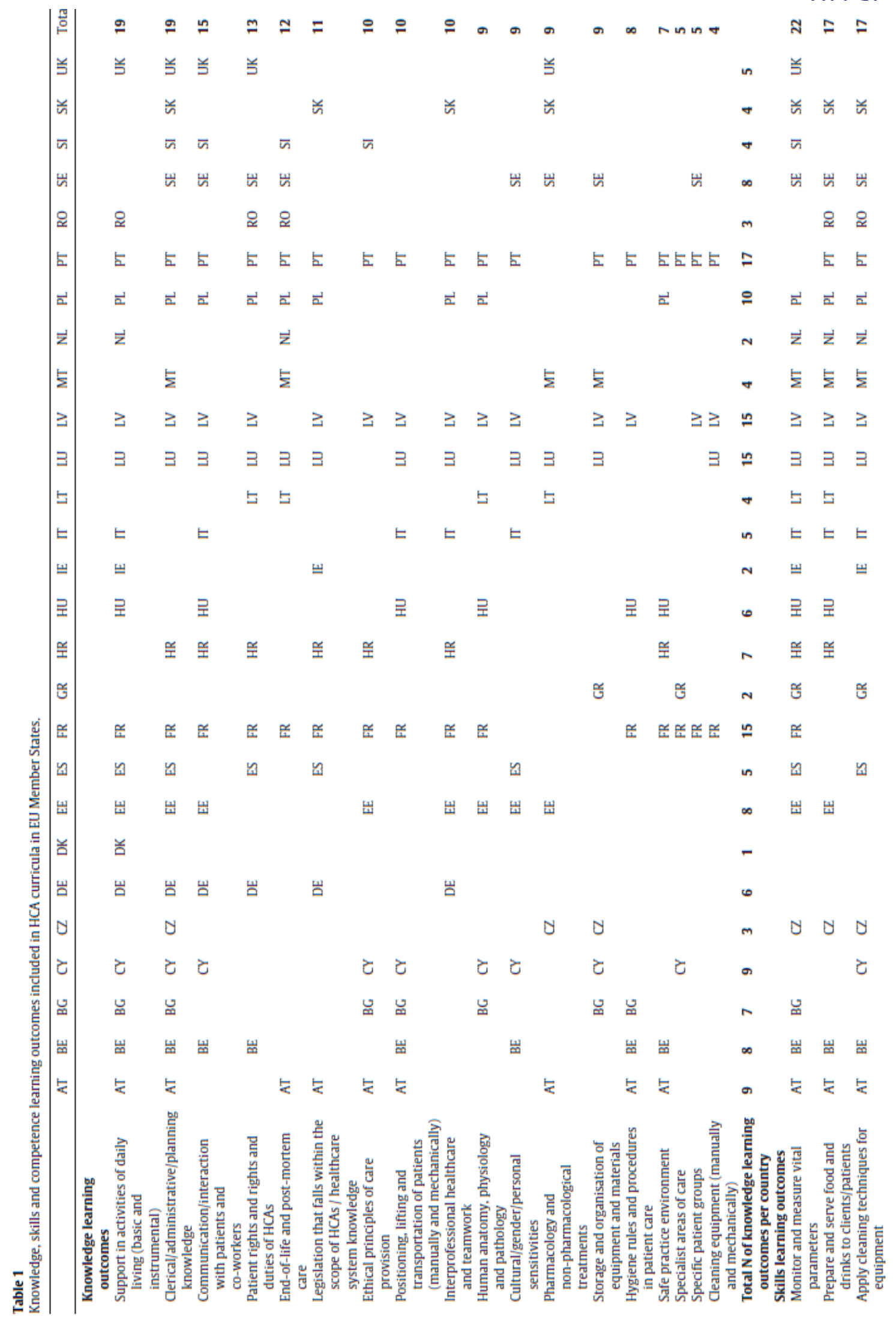


Kroezen, M., Schäfer, W., Sermeus, W., Hansen, J., Batenburg, R. Healthcare assistants in EU member states: an overview. Health Policy: 2018, 122(10), 1109-1117

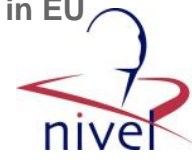

Table 2

Characteristics of the educational framework for HCAs across EU Member States.

\begin{tabular}{|c|c|c|c|c|}
\hline & Minimum age & Duration (standardised in years) & Theory-practice ratio & CPD requirements \\
\hline Austria & 17 & 1 year & $50: 50$ & - \\
\hline Belgium & 18 & 1 year & $50: 50$ & _- \\
\hline Bulgaria & 18 & - & No standard, but based on both & - \\
\hline Croatia & 15 & $\begin{array}{l}\text { Currently no programme. Foreseen } \\
\text { programme: } 4 \text { years }\end{array}$ & No standard, but based on both & Obligatory \\
\hline Cyprus & No minimum age & $\begin{array}{l}1 \text { year (certificate) - } 2 \text { years } \\
\text { (diploma) }\end{array}$ & $90: 10$ & No requirements \\
\hline Czech Republic & 15 & 4 years & $40: 60$ & _- \\
\hline Denmark & No minimum age & $8-12$ months & $40: 60$ & - \\
\hline Estonia & 18 & 2 years & $80: 20$ & Obligatory ( 16 hours per year) \\
\hline France & 17 & 10 months & $40: 60$ & Obligatory \\
\hline Germany (Lower Saxony) & 16 & 2 years & $65: 35$ & - \\
\hline Greece & No minimum age & 2 years & $60: 40$ & No requirements \\
\hline Hungary & 16 & 2 years & $50: 50$ & $\begin{array}{l}\text { Obligatory (a minimum of } 150 \\
\text { credit points from accredited } \\
\text { courses in a 5-year education } \\
\text { cycle) }\end{array}$ \\
\hline Ireland & No minimum age & 8 months (in general, part-time) & No standard, but based on both & - \\
\hline Italy & 17 & 1 year & $55: 45$ & - \\
\hline Latvia & 18 & 6 years & - & Obligatory ( 150 hours per year) \\
\hline Lithuania & 18 & 3 months & $40: 60$ & Optional \\
\hline Luxembourg & 15 & 3 years & $50: 50$ & Obligatory ( 40 hours per year) \\
\hline Malta & No minimum age & $\begin{array}{l}6 \text { months (EQF } 1 \text { ) to } 1-2 \text { years (EQF } \\
2-4 \text { ) }\end{array}$ & No standard, but based on both & No requirements \\
\hline Netherlands & No minimum age & $1-3$ years & No standard, but based on both & _ \\
\hline Poland & 16 & 2 years & $80: 20$ & - \\
\hline Portugal & No minimum age & 3 years & $85: 15$ & Optional \\
\hline Romania & 16 & 3 months & $1: 3$ & Obligatory \\
\hline Slovakia & $\begin{array}{l}15 \text { for fulltime; } 18 \text { for } \\
\text { part-time }\end{array}$ & 4 years & $50: 50$ & Obligatory \\
\hline Slovenia & 15 & 4 years & $60: 40$ & - \\
\hline Spain & 16 & 2 years & $70: 30$ & - \\
\hline Sweden & $\begin{array}{l}\text { No minimum age for upper } \\
\text { secondary school; } 20 \text { for } \\
\text { adult education }\end{array}$ & $21 / 4$ years & $90: 10$ & No requirements \\
\hline United Kingdom & No minimum age & Not regulated & No standard, but based on both & - \\
\hline
\end{tabular}

Legend: - means no info available.

Fig. 1. Average number of knowledge, skills and competence learning outcomesincluded in the HCA curriculum by type of entry regulation.

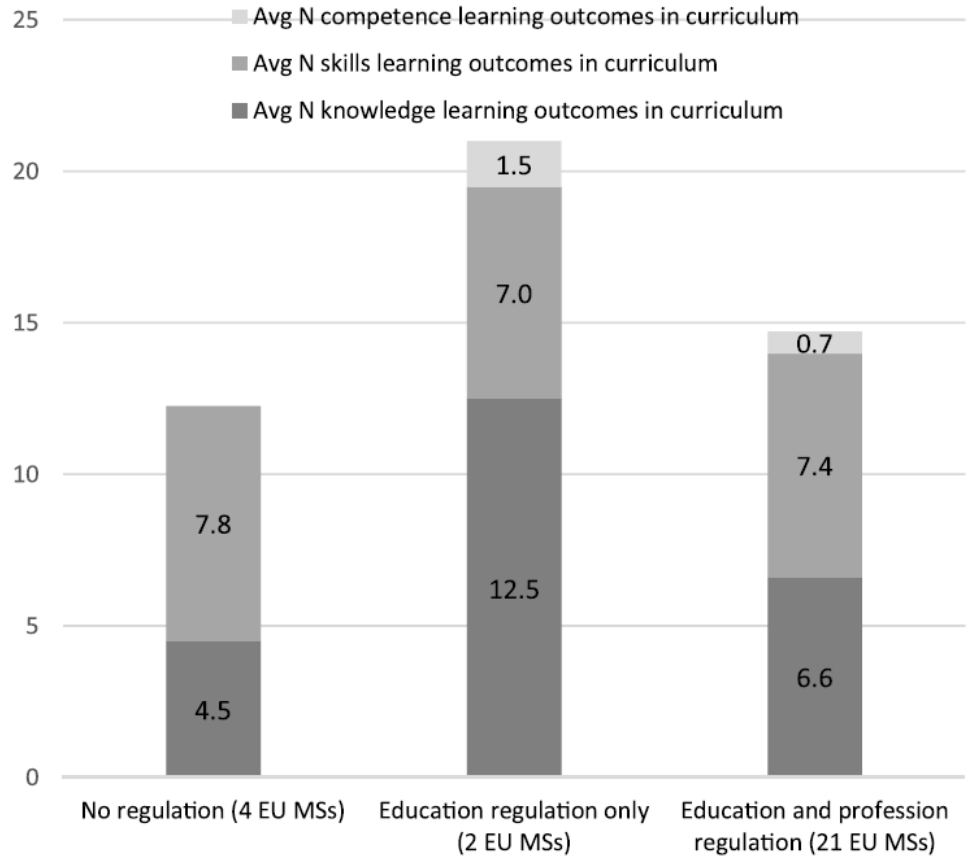


Kroezen, M., Schäfer, W., Sermeus, W., Hansen, J., Batenburg, R. Healthcare assistants in EU member states: an overview. Health Policy: 2018, 122(10), 1109-1117

Fig. 2. Average number of knowledge, skills and competence learning outcomesincluded in the HCA curriculum by theory-practice ratio of the curriculum.Note: no data were available on the theory-practice ratio for Latvia, hence Latvia isexcluded from the Figure

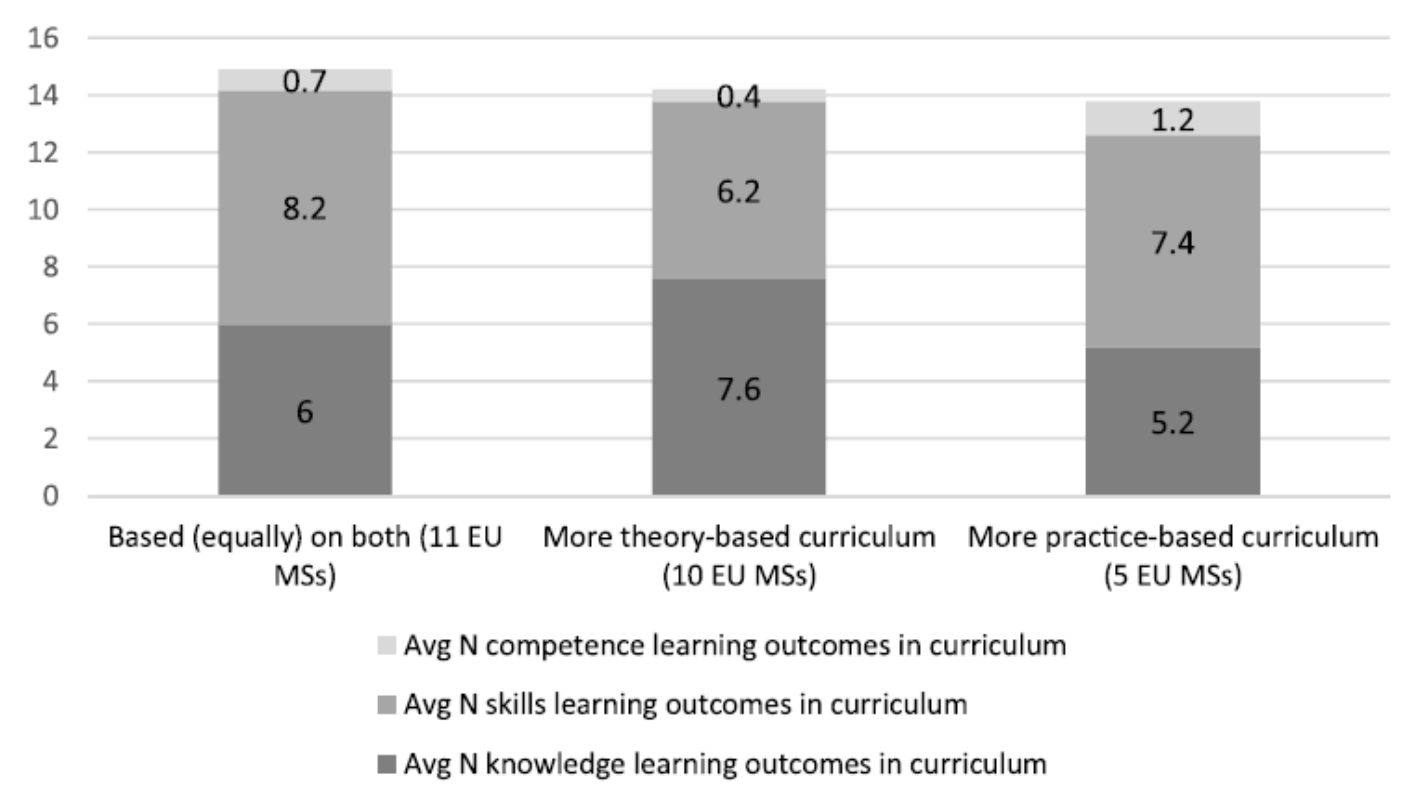

